\title{
Determinants of Adolescent Hookah Pipe Use: A Systematic Review
}

\section{Zainab Kader, Nicolette Vanessa Roman \& Rik Crutzen}

To cite this article: Zainab Kader, Nicolette Vanessa Roman \& Rik Crutzen (2019) Determinants of Adolescent Hookah Pipe Use: A Systematic Review, Journal of Child \& Adolescent Substance Abuse, 28:6, 474-493, DOI: 10.1080/1067828X.2020.1789525

To link to this article: https://doi.org/10.1080/1067828X.2020.1789525

+ View supplementary material 둔

曲 Published online: 16 Jul 2020.

Submit your article to this journal $₫$

Џll Article views: 76

Q View related articles ¿

View Crossmark data ־

Citing articles: 1 View citing articles $๘$ 


\title{
Determinants of Adolescent Hookah Pipe Use: A Systematic Review
}

\author{
Zainab Kader ${ }^{\mathrm{a}}$ (D), Nicolette Vanessa Roman ${ }^{\mathrm{a}}$ (D), and Rik Crutzen ${ }^{\mathrm{b}}$ (D) \\ aniversity of the Western Cape, Cape Town, South Africa; ${ }^{\mathrm{b}}$ Maastricht University, Maastricht, The Netherlands
}

\begin{abstract}
Adolescent hookah pipe use is increasing at a rapid rate, thus posing a major public health concern globally. The hookah pipe is a gateway substance to other substances that may be more harmful. Yet, at present, little is known about why adolescents are so drawn to this mechanism. It is this gap that this study attempted to fill. This study, therefore, aimed to review the determinants of adolescent hookah pipe use. An electronic search of 12 databases identified studies investigating determinants of adolescent hookah pipe use. Twentyfive studies sampling a total of 88,988 adolescents who use the hookah pipe were included. This study found that adolescent hookah pipe use is determined by an interplay of family factors, peer/friends factors, individual factors, school factors, the actual hookah pipe mechanism, advertisements, and awareness of hookah pipe lounges or bars. Prevention and early intervention strategies aimed at reducing adolescent hookah pipe use is needed.
\end{abstract}

\section{KEYWORDS}

Determinants; hookah pipe; prevention and early intervention strategies; smoking; systematic review; tobacco

\section{Introduction}

Hookah pipe smoking is a global public health concern affecting people of all ages. Experimentation with hookah pipe smoking most often begins during adolescence (Roman et al., 2017; Van der Merwe et al., 2013). Adolescence is an overwhelming period in one's life where intense development occurs in preparation for adulthood (Gilmore \& Meersand, 2014; Sugar, 2014). In their endeavor to become independent and unique individuals (Gilmore \& Meersand, 2014), adolescents often engage risk-taking behaviors. It is, therefore, a period of learning, experiencing, and active experimentation (Sugar, 2014). As they develop, they establish norms and lifestyles congruent with the values and culture of their peers, school, families, and communities (Case-Smith \& O'Brien, 2014). During this vulnerable time, adolescents are easily influenced, seek peer approval, and are inquisitive (Louw \& Louw, 2014). Hence, it is not uncommon that experimentation of hookah pipe smoking begins in adolescence (Roman et al., 2017; Van der Merwe et al., 2013).
The hookah pipe is a way of smoking any smokable substance that may be legal or illegal (Castaňeda et al., 2016; Haskins, 2011). However, it is typically used to smoke flavored tobacco (Haskins, 2011), although some people mix cannabis with the tobacco (Jacobs et al., 2015) and/ or replace the water used in the vase of the hookah pipe with alcohol (Fielder et al., 2012). Others may drink alcohol or smoke other substances concurrently (Sterling \& Mermelstein, 2011). Therefore, hookah pipe smoking can be regarded as a gateway substance to the use of other substances, such as cigarettes, alcohol, or cannabis (Kandel \& Kandel, 2015; Merianos et al., 2018; Sterling \& Mermelstein, 2011).

The hookah pipe is usually smoked in specialized bars, restaurants, cafés, or even at home, particularly in groups (Hammal et al., 2008; Roskin \& Aveyard, 2009). Needless to say, tobacco companies have capitalized on this growing trend and have introduced new appealing flavors to increase the demand (Sepetdjian et al., 2008). Most hookah pipe users believe that hookah pipe smoking is less harmful and a healthier alternative to cigarette smoking (Castaňeda 
et al.,2016). This perception has resulted in the popularization and romanticizing of hookah pipe smoking over the last decade (World Health Organization [WHO], 2005, 2015).

However, Haroon et al. (2014) argue that even though hookah pipe smoking is perceived by users as less harmful than cigarette smoking, this is not the case, as it contains tobacco as well as toxins found in cigarettes, such as tar, nicotine, and carbon monoxide. This makes it hazardous not only for the user, but also for people in close proximity to the user as well as the environment (Koçak et al., 2017). In addition to the harmful toxins entering the body when smoking the hookah pipe, Haroon et al. (2014) and Waziry et al. (2017) mention other harmful long-term effects of hookah use, such as nicotine dependence, pulmonary dysfunction, cardiovascular disease as well as the transmission of infectious diseases, since the same mouth piece is passed from person to person. Hookah pipe smoking carries more than just health concerns as Sterling and Mermelstein (2011) found that hookah use in the last $30 \mathrm{~d}$ affects school performance in terms of average grades. These effects are concerning, especially for adolescents whose health and school performance is cardinal for the opportunities that they may be exposed to in future (Kola, 2014). If hookah pipe smoking is associated with so many concerns, why do adolescents use it? This study aimed to review determinants of adolescent hookah pipe use in order to understand why adolescents smoke the hookah pipe. This understanding is important so that it can guide the development and implementation of interventions since the behaviors, circumstances, and beliefs of the target group is paramount to the success of any intervention.

\section{Methods}

The review was prepared according to the Preferred Reporting Items for Systematic Reviews (PRISMA) standards (Moher et al., 2009). A protocol was prepared in advance. It can be accessed at: https://www.crd.york.ac.uk/prospero/ display_record.php?RecordID $=76814$

\section{Information sources and search strategy}

The study included peer reviewed data-based papers in English that were published between 2007 and 2017. The publication dates were selected based on a broad scope of literature done by the authors and study conclusions of Combrink et al. (2010), Daniels and Roman (2013), Jacobs et al. (2015), Senkubuge and Mayosi (2012), Theron et al. (2010), and Van der Merwe et al. (2013) which stated that hookah pipe research has significantly gained momentum during this period. Therefore, the researchers thought that it would be an opportune time to review the research. The following electronic databases were searched: Cumulative Index to Nursing \& Allied Health (CINAHL), Dentistry and Oral Sciences Source, Green File, Health Source-Consumer Edition, Health Source-Nursing/Academic Edition, Medline, PsycARTICLES, Sosindex, SPORTDiscus, Cochrane, Wiley, and PubMed. Keywords relating to determinants and hookah pipe use were used. The following three sets of keywords were used for each search (a) hookah pipe, (b) determinants, and (c) age group. Similar words were used within each set of keywords, for example (a) shisha and water pipe; (b) factors, predictor, reasons, perception, motivation, why, attitude, and belief; and (c) preadolescent and adolescents. The same keyword variations were used for all 12 databases. The search terms per database are included in the file labeled: "Supplementary Material A." Additionally, the reference lists of the retrieved articles were manually searched for potentially eligible studies.

\section{Review procedure}

The review process consisted of three rounds to identify appropriate studies for this study. Round one was focused on title screening. At this point, duplicates were removed. Round two was focused on abstract screening. Round three was focused on full text screening. At each round, articles that did not meet the eligibility criteria were eliminated. Thereafter, the reference lists of the eligible full texts were manually scanned for any relevant studies that could be included in this study. To establish reliability of eligible studies at 
the full text stage, a random selection of six articles were screened by all researchers and the results pertaining to inclusion and exclusion were discussed among all three researchers. Once consensus was reached, the primary researcher reviewed each of the remaining articles to determine the nature of the study and the determinants of adolescent hookah pipe use.

\section{Inclusion and exclusion criteria}

English full text and peer reviewed studies published in academic journals were included. Quantitative, qualitative, and mixed method studies focusing on the determinants, correlates, factors, motivation, predictors, reasons, perceptions, attitudes, and beliefs of hookah pipe use among adolescents within the timeframe (2007-2017) were included. Study outcomes included the determinants of adolescent hookah pipe use. Hookah pipe use included experimentation only, continued use, ever use, or recent use. Intervention studies, animal studies, studies that focused solely on any other form of tobacco (such as cigarettes or e-cigarettes) besides hookah pipe guidelines, protocols, legislation, editorials, reviews, and discussion papers, were excluded.

\section{Quality assessment}

All studies meeting the inclusion criteria underwent quality assessment. The following appraisal tools were designed for this study: (1) adapted qualitative appraisal tool (Critical Appraisal Skill Program [CASP], 2014), (2) adapted quantitative appraisal (Roman \& Frantz, 2013), and (3) adapted mixed methods appraisal tool (Roman \& Frantz, 2013). However, the results of the study included only quantitative studies; therefore, the adapted quantitative appraisal (Roman \& Frantz, 2013) was used in this study, since the use of the tool was based on the methodology of the included study. The methodological quality was assessed on sampling methods, measurement tools, source of data, ethics, reference to hookah pipe and specific age group, research design, and appropriateness of method. The quality of the studies was rated using a percentage score. Based on the content of the manuscripts, each component was assessed and rated according to a three-grade scale: good (67-100\%), satisfactory (34-66\%), or bad (0-33\%). Two researchers independently assessed the quality of the included studies. Disagreements between the two reviewers were discussed until consensus was reached. The opinion of a third researcher was consulted to come to agreement in case of indecisions.

\section{Data extraction}

Once consensus was reached around the inclusion and exclusion of studies, the data from the included studies were extracted and placed in a data extraction tool which was developed and piloted prior to the search. The data was extracted by one researcher and verified by the other two researchers so that accuracy of extraction was confirmed by all three researchers. In the event of any disagreements, discussions were held to gain consensus. This was done to strengthen the quality of analysis of the included studies and to not exclude studies immediately that could potentially be eligible. The data was extracted from eligible studies and tabulated into Microsoft Excel. The following data were extracted: the author, year of study, sample details, number of participants, mean age or age range of participants, gender distribution of participants, relevant variables (determinants), and the associations of these relevant variables (determinants) with hookah pipe use (e.g. odds ratio $[\mathrm{OR}])$.

\section{Data analysis}

Narrative synthesis using thematic analysis was used in this study because each study reported the strength of the determinant differently, for example, some made use of OR, whilst others made use of percentage, Nagelkerke $R^{2}$, or crude prevalence ratio (PR). The relevance of the determinants was based on the effect size of the associations with the outcome of interest. The data was analyzed according to the study properties and the strength of the association. This meant that the greater the odds or higher the percentage, the more relevant the determinant for hookah pipe use. Once all the results were presented 


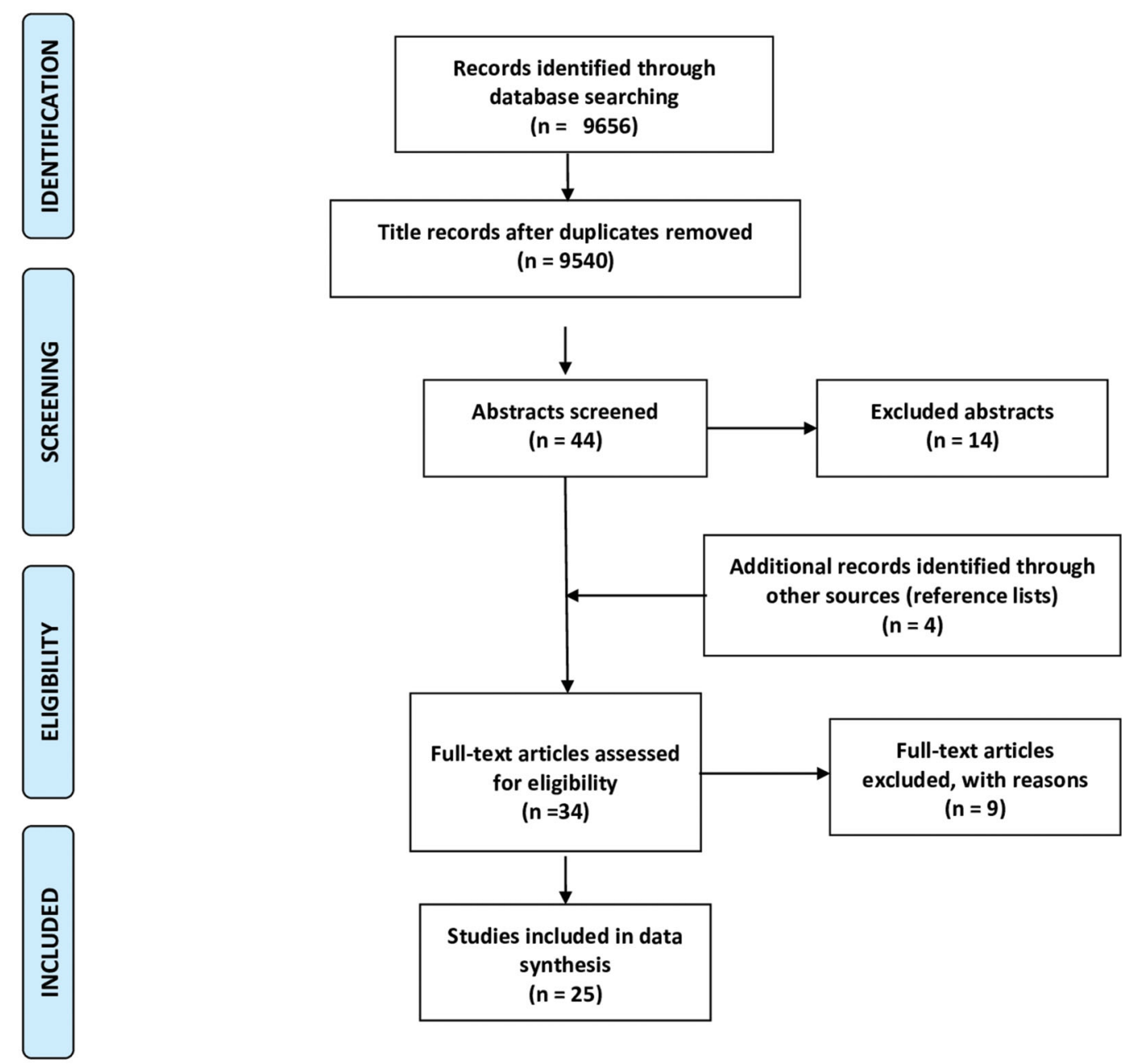

Figure 1. Flow diagram of the review process methodology using the PRISMA standards.

and analyzed, the researcher further analyzed all the results and then identified the most relevant determinants of hookah pipe use amongst adolescents and grouped them into family factors, peers/friends factors, individual factors, school factors, and other factors.

\section{Results}

Hookah pipe use included experimentation only, continued use, ever use, or recent use. The search yielded 9656 hits. After removal of duplicates $(n=116), 9540$ title records were screened. Titles that did not meet the inclusion criteria were excluded. Forty-four abstracts were screened for eligibility, only 30 of these records were found eligible for the study. The reference list of these records was scanned to identify any potentially eligible studies. Four references were found eligible. This resulted in 34 studies being eligible for the final step (full text review) of determining appropriate studies that would be included in the review. Nine studies were excluded. The reasons for exclusion include: (a) intervention study $(k=1)$, (b) did not report associations $(k=6)$, and (c) only reported on tobacco and alcohol use but did not specify hookah use $(k=2)$. During data extraction, only one study used a qualitative methodology while the remainder of the sample made use of a quantitative methodology. For this reason, the three researchers decided to exclude this study post hoc. The final sample for this review comprised 25 studies. Figure 1 shows the flow diagram of the review process.

\section{Study characteristics}

Seventy-two percent of the studies were from Asia, $16 \%$ were from North America, $8 \%$ were 
from South America, and 4\% were from Europe. The majority of the studies used a cross-sectional study research design (84\%). The remainder of the studies made use of longitudinal (8\%), quasi-experimental (4\%), and prospective (4\%) research designs. Studies referred to hookah pipe use as past, current, or ever use.

\section{Methodological quality}

The methodological quality of the studies was assessed using eight items that were derived from validated methodological quality rating scales (Roman \& Frantz, 2013). The studies satisfied an average of $86 \%$ of the criteria, with $88 \%$ of the studies considered strong, and $12 \%$ of the studies considered moderate, indicating moderate to strong methodological quality. All studies focused on children aged 10-19 and made reference to the hookah pipe. All 25 studies made use of appropriate quantitative methods and successfully addressed the research questions with appropriate research designs. All studies reported their measures but only $56 \%$ reported on the reliability and validity of this measured in the respective studies. Majority of studies made use of primary data sources $(76 \%)$. Seventy-two percent of the studies reported that ethical approval was obtained, the remainder of the studies did not report on ethical approval. Table 1 shows the methodological quality of the studies used to identify the determinants of adolescent hookah pipe use.

\section{Sample characteristics}

Only preadolescents and adolescents aged 10-19 years old that use the hookah pipe were considered for analysis in this study. Age is reported differently in the studies; therefore, a mean age cannot be reported across all studies, nor can an age range be conclusively reported. Forty-six percent of the study sample were female and $96 \%$ of the population was school going students; hence, the sample was drawn from the school population. Shujaat et al. (2013) studied the general population visiting hookah pipe bars, hookah pipe cafés, and tobacco shops, and that is how he drew his sample. In total, 88,988 adolescents were studied across the 25 included studies.

\section{Determinants of hookah pipe use amongst adolescents}

Table 2 identifies the determinants of adolescent hookah pipe use and highlights the relevance of the determinants regarding adolescent hookah pipe use. Table 3 places the relevant determinants into themes. The most dominant themes were the family factors, peer/friends factors, individual factors, and school factors, while the factors that could not be placed under these themes were referred to as "other" factors. Tables 2 and 3 are presented below followed by a discussion of each theme. All references were given an alphabetic code and are, therefore, reported with a code in the next section. The alphabetic codes are listed in Table 2.

\section{Family determinants}

A number of significant family factors emerged. Two subthemes were identified from the family factors: (1) parents' or sibling tobacco use and adolescents' perception of how parents would respond to their hookah pipe use and (2) parents' education levels and employment status or occupation.

Theme 1: Parents' or sibling tobacco use and adolescents' perception of how parents would respond to their hookah pipe use. Adolescents' hookah pipe use is determined by the smoking habits of one or both parents (particularly the father), siblings (particularly brothers) as well as other family members ${ }^{\mathrm{b}-\mathrm{d}, \mathrm{h}, \mathrm{i}, \mathrm{k}-\mathrm{m}, \mathrm{s}}$. Adolescents who lived in a home where hookah pipe is used are 10.55 times more likely to use the hookah pipe $(\mathrm{OR}=10.55 ; 95 \% \mathrm{CI}, 7.32-15.20)^{\mathrm{m}}$. Higher odds of hookah pipe smoking among adolescents is determined by fathers who smoke $(\mathrm{OR}=9.73$, $p=0.001)^{\mathrm{d}}$, parents who smoke $(\mathrm{OR}=4.75 ; 95 \%$ $\mathrm{CI}, 1.38-12.35)^{1}$, hookah smoking siblings (OR = 4.01; 95\% CI, 2.76-5.8) $)^{\mathrm{m}}$, brothers who smoke the hookah pipe $(\mathrm{OR}=5.18, p=0.001)^{\mathrm{d}}$, and fathers and brothers who smoke the hookah pipe $(\mathrm{OR}=6.67, p=0.001)^{\mathrm{d}}$. Having other family members who smoke the hookah pipe increases 


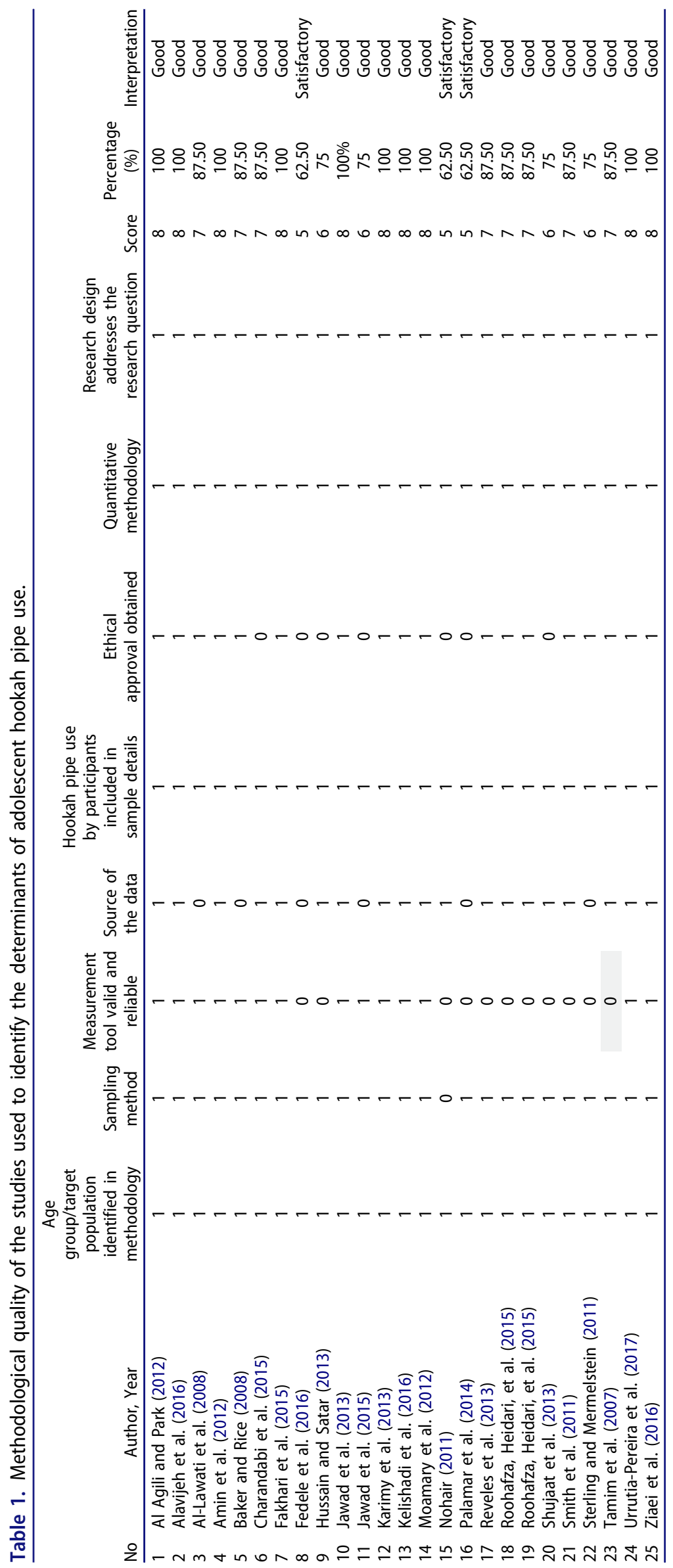




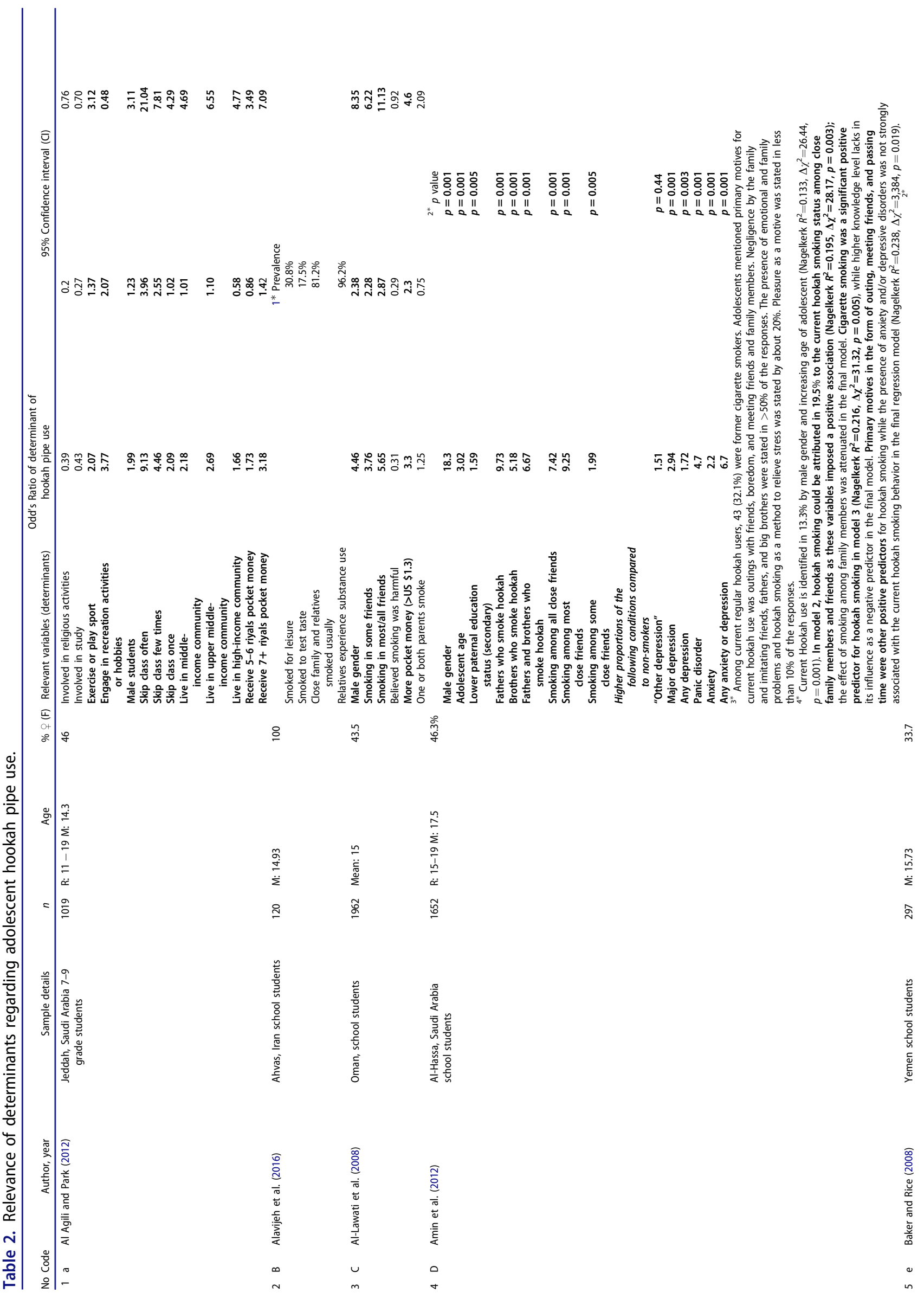


JOURNAL OF CHILD \& ADOLESCENT SUBSTANCE ABUSE $\Leftrightarrow 481$

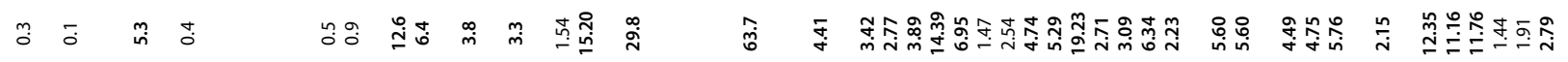

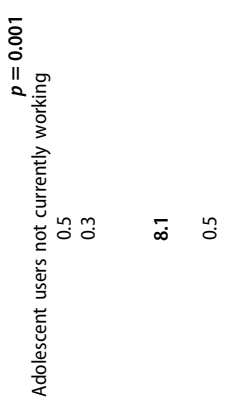

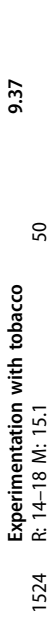

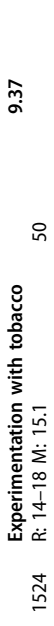

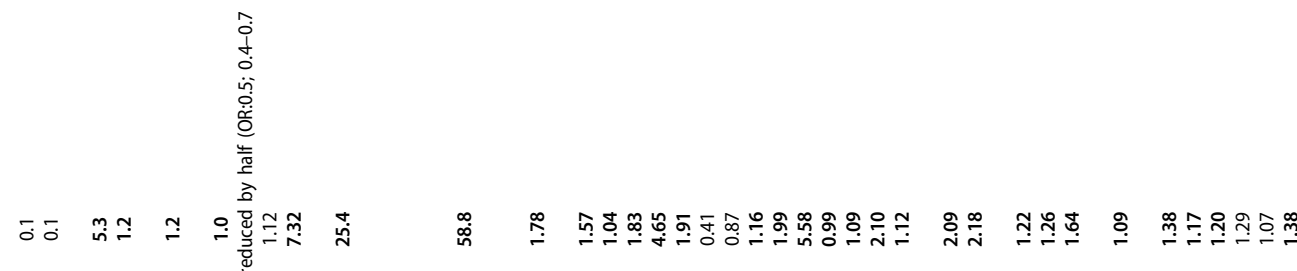
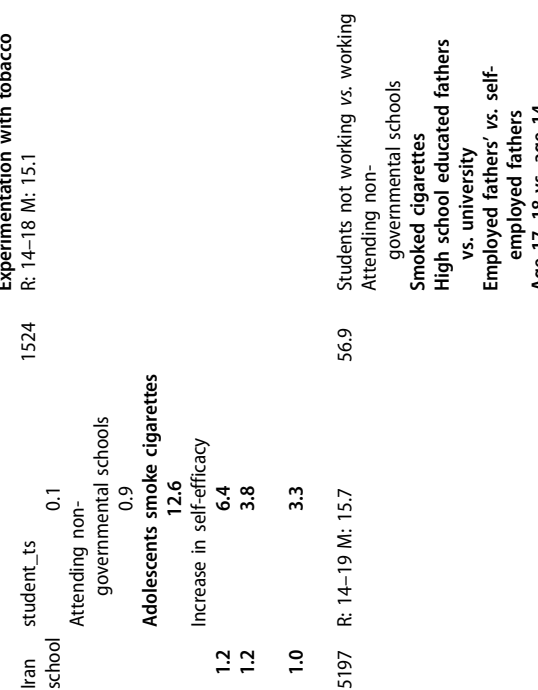

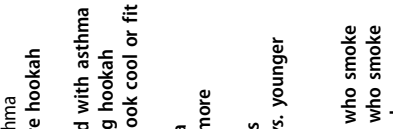

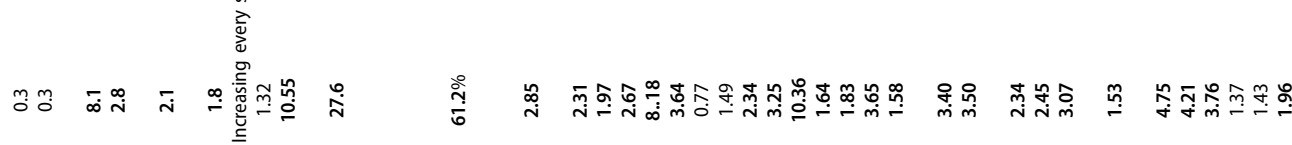
兽

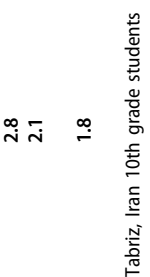

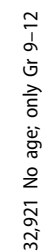

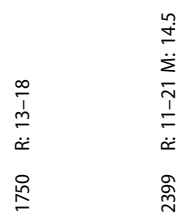

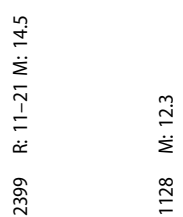

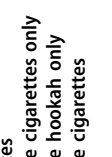

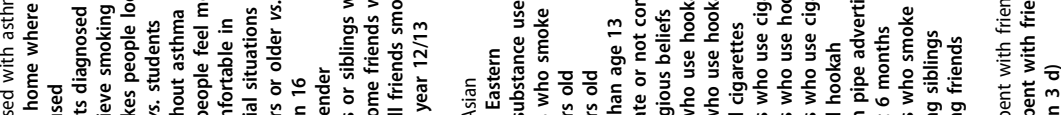

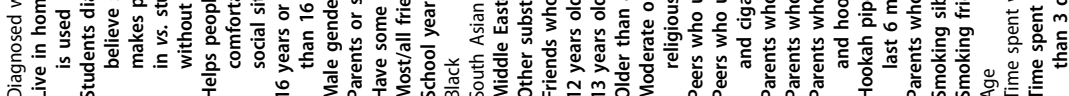

:

ơ

F

总

in

-

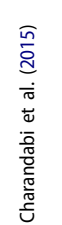

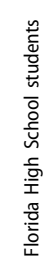
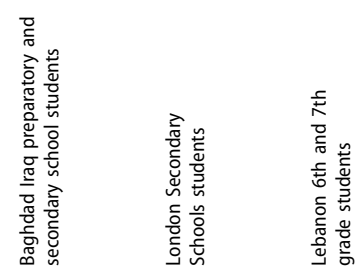

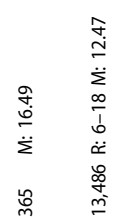

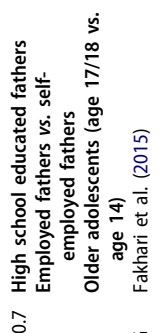

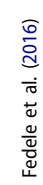

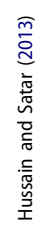

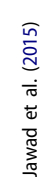

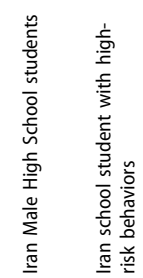



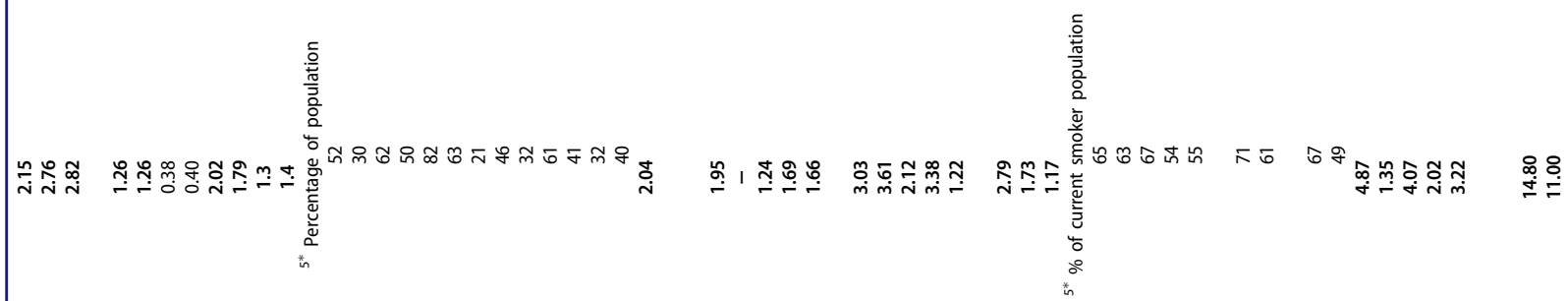

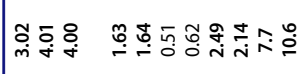

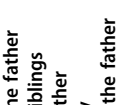

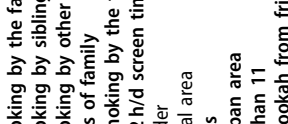

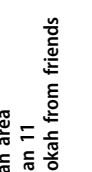

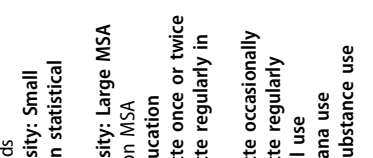

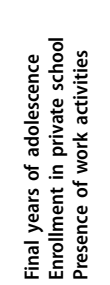

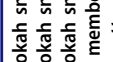

侘

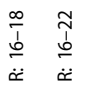

ปิ

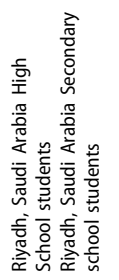

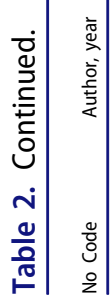

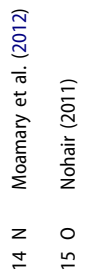

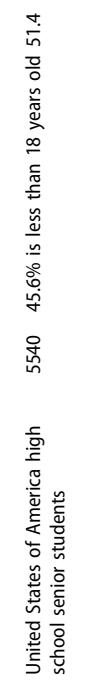

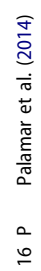

䑻 in

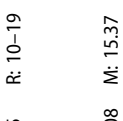

台学
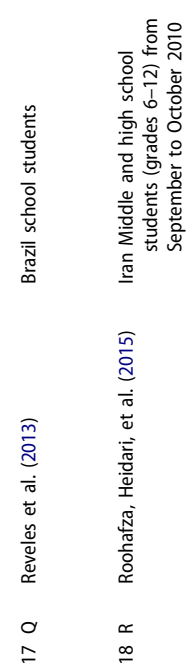

in

$$
\begin{aligned}
& \stackrel{\bar{s}}{\stackrel{\bar{z}}{\ddot{\Sigma}}} \\
& \text { 通 }
\end{aligned}
$$

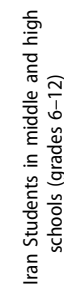

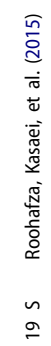




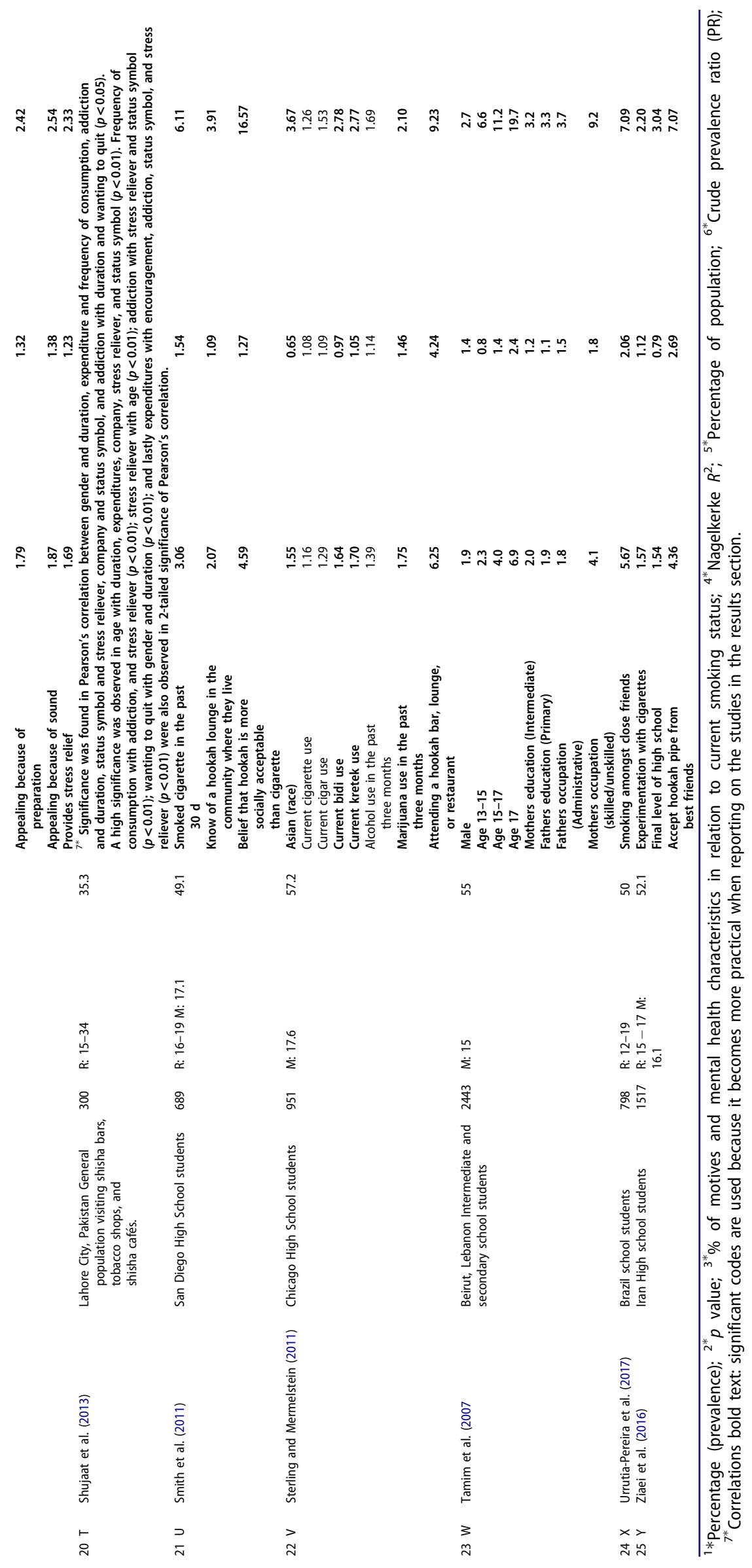


Table 3. Most relevant determinants regarding adolescent hookah pipe use.

\begin{tabular}{|c|c|c|c|c|}
\hline Family factors & Peers/friends factors & Individual factors & School factors & Other factors \\
\hline 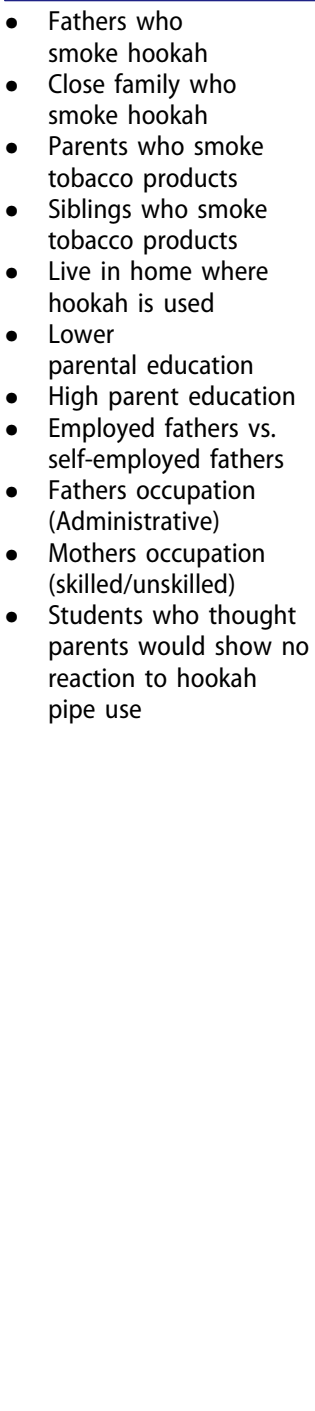 & $\begin{array}{l}\text { - } \text { Smoking in friends } \\
\text { - } \text { Peers who use } \\
\text { - Pookah only } \\
\text { - } \text { and cigarettes } \\
\text { - } \text { Outings with friends } \\
\text { - } \text { Meeting friends } \\
\text { - Passing time } \\
\text { - } \text { with friends } \\
\text { - } \text { (more than } 3 \text { d) } \\
\text { - } \text { frcepting hookah } \\
\text { - Accepting hookah from } \\
\text { best friend } \\
\text { - Status symbol } \\
\text { amongst peers } \\
\text { - Company/peer group } \\
\text { - Encouragement } \\
\text { from peers } \\
\text { Engage in recreation } \\
\text { activities or hobbies }\end{array}$ & 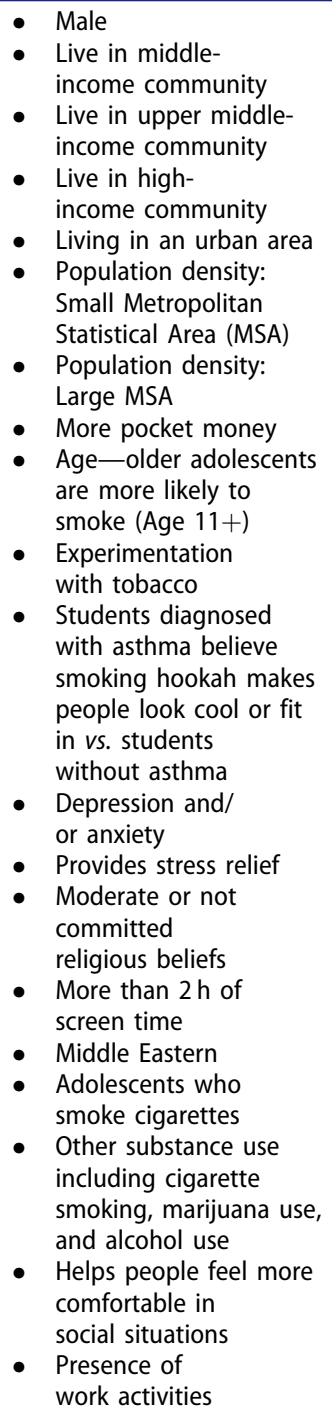 & $\begin{array}{ll}\text { - } & \text { Skip class } \\
\text { - } & \text { School year } 12 / 13 \\
\text { (approx. age 16/17) } \\
\text { - } & \text { Final level of } \\
& \text { high school } \\
\text { - } & \text { Enrollment in } \\
\text { private school }\end{array}$ & $\begin{array}{l}\text { - } \text { Taste } \\
\text { - } \text { Smell } \\
\text { - } \text { Preparation methods } \\
\text { Hookah pipe } \\
\text { advertisement in the } \\
\text { last } 6 \text { months } \\
\text { - Sound } \\
\text { - Awareness of hookah } \\
\text { bar, restaurant, or } \\
\text { lounge in community }\end{array}$ \\
\hline
\end{tabular}

the likelihood of adolescents smoking the hookah pipe by four times $(\mathrm{OR}=4.00 ; 95 \% \mathrm{CI}$, $2.82-5.67)^{\mathrm{m}}$. Eighty-one percent of adolescent respondents reported having close family or relatives that regularly smoked and $96.2 \%$ reported relatives who had experience of substance abu$\mathrm{se}^{\mathrm{b}}$. Sixty-two percent of adolescents reported smoking the hookah pipe because they were imitating their fathers and brothers ${ }^{\mathrm{d}}$. Seventythree percent of adolescents felt that their families were negligent, and this served as a motive to smoke ${ }^{\mathrm{d}}$. Adolescents who thought that their parents would show no reaction to their hookah pipe use were 3.89 times more likely to smoke the hookah pipe (OR $=3.89 ; 95 \%$ CI, 3.22-4.71) .
Theme 2: Parents' education levels and employment status or occupation. Adolescent hookah pipe use is determined by fathers' and mothers' education levels and occupations ${ }^{\mathrm{d}, \mathrm{f}, \mathrm{g}, \mathrm{p}, \mathrm{w}}$. Three of the five studies focused on fathers only ${ }^{\mathrm{d}, \mathrm{f}, \mathrm{g}}$; one study did not specify which parent and made reference to parent education ${ }^{\mathrm{p}}$; and one study focused on fathers' and mothers' education levels and type of employment ${ }^{\mathrm{w}}$. Parents who did not attend university and only had a high school education were considered to have lower education levels ${ }^{\mathrm{d}, \mathrm{g}, \mathrm{p}, \mathrm{w}}$.

Adolescents who have fathers with lower education levels were 1.59-2.8 times more likely to smoke the hookah pipe $(\mathrm{OR}=1.59, p=0.001)$ $(\mathrm{OR}=2.8 ; 95 \% \mathrm{CI}, \quad 1.2-6.4)^{\mathrm{d}, \mathrm{f}, \mathrm{g}, \mathrm{w}}$, whereas 
adolescents who have mothers with lower education levels were twice as likely to smoke the hookah pipe $(\mathrm{OR}=2.0 ; 95 \% \text { CI, } 1.2-3.2)^{\mathrm{w}}$. Unspecified parents' education increased the odds of adolescent hookah pipe use by 1.58 times (OR $=1.58 ; 95 \%$ CI, $1.24-2.02)^{\mathrm{p}}$. Employed fathers increased the likelihood of adolescents smoking hookah by 2.1 times compared to self-employed fathers $(\mathrm{OR}=2.1 ; 95 \% \mathrm{CI}, 1.2-3.8)^{\mathrm{f}}(\mathrm{OR}=2.1$; 95\% CI, 1.2-3.8 $)^{\mathrm{g}}$. Fathers with an administrative job increased the likelihood of adolescent hookah smoking by 1.8 times $(\mathrm{OR}=1.8 ; 95 \% \mathrm{CI}$, $1.5-3.7)^{\mathrm{g}}$. The odds of adolescent smoking was 4.1 times more likely if mothers were employed, irrespective of whether the occupation required her to be skilled or unskilled (OR = 4.1; 95\% CI, 1.8-9.2) ${ }^{\mathrm{w}}$.

\section{Peers/friends determinants}

Factors pertaining to adolescents' peers and friends are significant determinants of hookah pipe use. Three subthemes emerged from the peer/friends factors: (1) peers and friends who smoke, (2) socializing with friends, and (3) encouragement and status symbol amongst peers.

Theme 1: Peers and friends who smoke. Smoking amongst close friends is a strong determinant of adolescent hookah pipe use. More specifically, smoking among all close friends increased the likelihood by 7.42 times $(\mathrm{OR}=7.42, p=0.001)^{\mathrm{d}}$ and smoking among most close friends increased the likelihood by 9.25 times $(\mathrm{OR}=9.25$, $p=0.001)^{\mathrm{d}}$. However, having any friends that smoke increases the odds of adolescents using the hookah pipe by 2.67-10.36 times $(\mathrm{OR}=2.67$; $95 \%$ CI, 1.83-3.89 $)^{\mathrm{i}}(\mathrm{OR}=10.36 ; 95 \% \mathrm{CI}$, $5.58-19.23)^{j}$. These results indicate that the peer group has a significant influence on determining adolescent hookah pipe use. These findings are corroborated by $61 \%$ of respondents who confirmed their friends' influence on their hookah pipe smoking behavior ${ }^{\mathrm{x}}$.

Theme 2: Socializing with friends. Socializing with friends was reported by adolescents as the main predictor of hookah pipe use. Outings with friends (87.3\%), meeting friends $(76.1 \%)$, and escaping boredom/passing time (78.4\%) were their most cited reasons for hookah smoking ${ }^{\mathrm{d}}$. Forty percent of respondents reported that they smoke the hookah pipe to sit with friends $(40 \%)^{\mathrm{o}}$, have fun with friends $(54 \%)^{\mathrm{r}}$, or because everyone smokes so it's considered good entertainment $(55 \%)^{\mathrm{r}}$. Adolescents who spent more than three consecutive days with friends were 1.96 times more likely to smoke the hookah pipe $(\mathrm{OR}=1.96 ; 95 \% \mathrm{CI}, 1.38-2.79)^{\mathrm{m}}$. It was also found that adolescents who engage in recreational activities or hobbies are 3.77 times more likely to smoke the hookah pipe $(\mathrm{OR}=3.77 ; 95 \%$ CI, 1.37-3.12) .

Theme 3: Encouragement and status symbol amongst peers. Accepting hookah from a friend was more likely $(\mathrm{OR}=10.6 ; 95 \% C I, 1.4-83.4)^{\mathrm{n}}$ to motivate one to smoke compared to accepting hookah from a best friend $(\mathrm{OR}=4.36 ; 95 \% \mathrm{CI}$, $2.69-7.07)^{\mathrm{y}}$. Sixty-one percent of respondents felt their friends encouraged them to smoke ${ }^{t}$. While 69\% perceived smoking the hookah pipe as a status symbol, making them feel more admired by their peers ${ }^{t}$.

\section{Individual determinants}

Individual factors also play an important role in hookah pipe use. Four subthemes emerged from the individual factors: (1) demographics, religion, pocket money, and screen time; (2) living conditions; (3) substance experimentation or use, and (4) physical or mental health. These are described below in more detail.

Theme 1: Demographics, religion, pocket money, and screen time. All studies that considered gender reported that being male is a determinant for hookah pipe use $\mathrm{a}^{\mathrm{a}, \mathrm{d}, \mathrm{i}, \mathrm{m}, \mathrm{s}, \mathrm{w}}$. One study found that being male increased the odds of hookah pipe smoking by 18.3 times $(\mathrm{OR}=18.3, p=0.001)^{\mathrm{d}}$. In terms of age, clear distinctions cannot be made whether younger adolescents are more likely to smoke hookah pipe compared to older adolescents, or vice versa, because adolescents in the final year of adolescence are 6.54 times more likely $(\mathrm{OR}=6.54 ; 95 \% \mathrm{CI}, 2.79-15.32)^{\mathrm{q}}$ to smoke hookah, but adolescents eleven years old and older are 7.7 times more likely to smoke $(\mathrm{OR}=$ $7.7 ; 95 \% \mathrm{CI}, 1.3-43.6)^{\mathrm{n}}$. It is unclear what the 
mean age is for the respondents that are older than eleven years old; therefore, clear conclusions cannot be made, but it is evident that adolescents are very likely to smoke the hookah pipe based on these results. Respondents who identified themselves as Asian (OR $=1.55 ; 95 \% \mathrm{CI}$, $0.65-3.67)^{\mathrm{v}}$ or Middle Eastern $(\mathrm{OR}=2.34 ; 95 \%$ CI, $1.16-4.74)^{\mathrm{j}}$ proved to be more likely to use the hookah pipe compared to adolescents from other backgrounds. Furthermore, adolescents who had moderate or non-committed religious beliefs were 1.58 times more likely to smoke the hookah pipe $(\mathrm{OR}=1.58 ; 95 \% \text { CI, 1.12-2.23 })^{\mathrm{k}}$ compared to adolescents who reported having committed religious beliefs. Participants who had more than $2 \mathrm{~h}$ screen time were 1.64 times more likely to smoke the hookah pipe $(\mathrm{OR}=1.64 ; 95 \% \mathrm{CI}$, $1.26-2.14)^{\mathrm{m}}$ compared to less than $2 \mathrm{~h} / \mathrm{d}$ screen time. The amount of pocket money received also increased the likelihood of smoking the hookah pipe. In one study, adolescents who received 5-6 Saudi riyals were 1.73 times more likely (OR = $1.73 ; 95 \%$ CI, $0.86-3.49)^{\mathrm{a}}$ to smoke the hookah pipe compared to adolescents who received seven or more riyals. In the case of the latter, adolescents were $3.18(\mathrm{OR}=3.18 \text {; 95\% CI, 1.42-7.09) })^{\mathrm{a}}$ times more likely to smoke the hookah pipe. Similarly, adolescents who received more than 1.3 USD were 3.3 times more likely to smoke the hookah pipe $(\mathrm{OR}=3.3 ; 95 \% \mathrm{CI}, 2.3-4.6)^{\mathrm{c}}$.

Theme 2: Living conditions. Living conditions appear to be a significant factor for determining hookah pipe use. Adolescents living in small metropolitan statistical areas that are densely populated are 2.67 times more likely to smoke the hookah pipe $(\mathrm{OR}=2.67 ; 95 \% \mathrm{CI}$, 2.04-3.49) $)^{\mathrm{p}}$. Similarly, adolescents living in large metropolitan statistical areas that are also densely populated are 2.64 times more likely to smoke the hookah pipe $(\mathrm{OR}=2.64 ; 95 \% \mathrm{CI}$, $1.95-3.56)^{\mathrm{p}}$. Conversely, living in an urban area makes one 1.87 times more likely to smoke the hookah pipe $(\mathrm{OR}=1.87 \text {; 95\% CI, } 1.35-2.58)^{\mathrm{s}}$.

Likewise, living in a middle-income community makes adolescents 2.18 times more likely $(\mathrm{OR}=2.18 ; 95 \% \mathrm{CI}, 1.01-4.69)^{\mathrm{a}}$ to smoke the hookah pipe, whereas living in an upper middleincome community makes one 2.69 times more likely to smoke the hookah pipe $(\mathrm{OR}=2.69$; 95\% CI, 1.10-6.55) $)^{\mathrm{a}}$. However, living in a highincome community makes one 1.66 times more likely to smoke $(\mathrm{OR}=1.66 ; 95 \% \mathrm{CI}, 0.58-4.77)^{\mathrm{a}}$. These results show that living in higher income communities makes adolescents less likely to smoke the hookah pipe compared to middleincome and upper middle-income communities, or areas that are densely populated.

Theme 3: Substance experimentation or use. Past, present, or ever-use of cigarette smoking is a strong determinant of hookah pipe use ${ }^{\text {e,f,g,p,u,y }}$, followed by marijuana use $^{\mathrm{p}}$, alcohol $\mathrm{use}^{\mathrm{p}}$, and other substance $\mathrm{use}^{\mathrm{j}, \mathrm{p}}$. When adolescents experiment with tobacco, they are 9.37 times more likely to smoke the hookah pipe $(\mathrm{OR}=9.37 ; p=0.001)^{\mathrm{e}}$. This is especially true if the form of tobacco smoked is cigarettes because this makes adolescents 8.1 times more likely $(\mathrm{OR}=8.1 ; 95 \% \mathrm{CI}, 5.3-12.6)^{\mathrm{f}}$ to smoke the hookah pipe. Adolescents who have ever used marijuana are 4.48 times more likely to smoke the hookah pipe compared to those that have not used marijuana $(\mathrm{OR}=4.48 ; 95 \% \quad \mathrm{CI}, 3.38-5.94)^{\mathrm{p}}$. Adolescents who have ever used alcohol are 3.34 times more likely to smoke the hookah pipe compared to those who have not used alcohol (OR = 3.34; 95\% CI, 2.12-5.25) $)^{\mathrm{p}}$.

Theme 4: Physical or mental health. Hookah pipe is commonly used among people who have physical or mental health concerns. In the views of students diagnosed with asthma, $28 \%$ are convinced that smoking the hookah pipe makes them look cool and fit in with their peer groups, while $61 \%$ reported that it makes them feel more comfortable in social situations ${ }^{\mathrm{h}}$. Adolescents with any anxiety or depression are 6.7 times more likely to smoke the hookah pipe compared to adolescents who do not experience anxiety or depressive symptoms or disorders $(\mathrm{OR}=6$, $p=0.001)^{\mathrm{d}}$. Adolescents reported smoking the hookah pipe after a bad event (65\%), when they feel angry (63\%), and when they feel distressed because it relaxes them $(67 \%)^{\mathrm{r}}$.

\section{School determinants}

School determinants can all be grouped in one theme, namely, attending school. Adolescents 
who engage in class truancy are 9.13 times more likely to smoke the hookah pipe compared to those who do not skip class often $(\mathrm{OR}=9.13$; 95\% CI, 3.96-21.04) $)^{\mathrm{a}}$. Adolescents who have skipped class a few times are 4.46 times more likely to smoke the hookah pipe compared to those who do not skip class (OR $=4.46 ; 95 \% \mathrm{CI}$, $2.55-7.81)^{\mathrm{a}}$, while those who have skipped class once are 2.09 times more likely to smoke the hookah pipe compared to those who have never been truant $(\mathrm{OR}=2.09 ; 95 \% \mathrm{CI}, 1.02-4.29)^{\mathrm{a}}$. Furthermore, adolescents who are enrolled at private schools are 2.23 times more likely to use the hookah pipe $(\mathrm{OR}=2.23 ; 95 \% \mathrm{CI}, 1.73-2.88)^{\mathrm{q}}$. Adolescents in their final level of high school are 1.54 times more likely to smoke the hookah pipe compared to those at other levels $(\mathrm{OR}=1.54$; 95\% CI, 0.79-3.04) $)^{\mathrm{y}}$. However, another study found a higher odds of learners of this age group (16-18) smoking the hookah pipe $(\mathrm{OR}=3.64$; 95\% CI, 1.91-6.95) ${ }^{j}$. Although the difference cannot be definitively concluded, the one noticeable difference between the two studies is that the first one is located in Iran and the second one in London. Therefore, context may play a role in schooling and hookah pipe use. Additionally, $62 \%$ of adolescents reported that their teacher smokes cigarettes at school.

\section{Other determinants}

Factors that could not be placed under family, peers/friends, individual, or school factors were placed under "other" factors. Two themes emerged from this set of factors: (1) the hookah pipe mechanism or process and (2) awareness of hookah pipe smoking.

Theme 1: The hookah pipe mechanism or process. Adolescents found hookah pipe smoking appealing because it made them feel relaxed (50\%), they smoked for leisure $(30.8 \%)$, they had an interest in smoking (46\%), they attracted attention when they smoked (41\%), and they enjoyed the taste $(17.5 \%)^{\text {b.s.o }}$. These perceptions were corroborated by the findings of another study which found that hookah pipe smoking was 18.07 times more appealing to adolescent users because of the taste $\left(\mathrm{OR}=18.07 ; 95 \% \mathrm{CI}, 14.80-22.07^{\mathrm{s}}\right.$. Furthermore, adolescents were 13.40 times more likely to smoke the hookah pipe because of the sweet smell $(\mathrm{OR}=13.40 ; 95 \% \mathrm{CI}, 11.00-16.69)^{\mathrm{s}}$ and sound $(\mathrm{OR}=1.87 ; 95 \% \text { CI, 11.38-2.54) })^{\mathrm{s}}$. Enjoying preparing and setting up the hookah, adolescents were 1.79 times more likely to smoke the hookah pipe because of the preparation methods $(\mathrm{OR}=1.87 ; 95 \% \mathrm{CI}, 11.38-2.54)^{\mathrm{s}}$.

Theme 2: Awareness of hookah pipe smoking. Thirty-two percent of adolescents reported being motivated to smoke after seeing a hookah pipe smoking advertisement in the last six months ${ }^{\circ}$. Adolescents were 2.07 times more likely to smoke the hookah pipe when they knew of a hookah lounge in the community where they reside (OR $=2.07 ; 95 \%$ CI, 1.09-3.91) ${ }^{\mathrm{u}}$. Attending a hookah bar, lounge, or restaurant increased the odds of usage by 6.25 times $(\mathrm{OR}=6.25 ; 95 \% \mathrm{CI}$, $4.24-9.23)^{\mathrm{v}}$. Furthermore, owing to the perception that smoking the hookah pipe is more socially acceptable than smoking cigarettes, adolescents were 4.59 times more likely to smoke the hookah pipe $(\mathrm{OR}=4.59 ; 95 \% \mathrm{CI}, 1.27-16.57)^{\mathrm{u}}$.

\section{Discussion}

This review was conducted to discover the determinants of adolescent hookah pipe use in order to answer the research question: "why do adolescents use the hookah pipe?" This study found that hookah pipe use is determined by family, peer, individual, school, and other factors, such as use of the hookah pipe mechanism and hookah pipe awareness. These findings differ from the determinants of other nicotine products, such as e-cigarettes and cigarettes. In terms of the latter, Soneji et al. (2017) found that these may activate cognitive or behavioral processes that increase the risk of smoking and that users of these products may show increases in positive expectancies about cigarette smoking and increases in affiliation with peers who smoke these products. However, it has not been conclusively reported that affiliation with peers is a determinant for use. The findings of this study clearly identifies that the social milieu as a defining determinant of hookah pipe use, making hookah pipe use more of a social phenomenon compared to e-cigarettes or cigarette smoking, 
which appears to be the result of activating a cognitive or behavioral response (Soneji et al., 2017). This could be attributed to the fact that the hookah pipe is often smoked with friends and family, and therefore, its experienced effects are more than just physical

Oyewole et al. (2018) conducted a systematic review which focused on identifying tobacco use among Nigerian youth. In their research, they found similar results to this study. Being male increased the likelihood of using tobacco products, such as the hookah pipe. This could be related to the fact that male tobacco use is influenced by different cultural, psychosocial, and socioeconomic factors, which views male tobacco use as more favorable compared to female tobacco use (Oyewole et al., 2018; World Health Organization [WHO], 2018). The role of other substances cannot be minimized as substances, such as cigarettes and alcohol act as gateway substances for hookah pipe use, or vice versa. Also, adolescents tend to experiment with substances at a young age, and then as they get older, their usage may become more frequent to gain the same effects or they may experiment with more or different substances, such as the hookah pipe (Bracken et al., 2013).

Individuals and groups exist within a social context. It is not uncommon that environmental factors, such as residential settings, peer and media influences, and access to establishments where the hookah pipe is sold plays an integral role in whether one smokes or not (Hawkins et al., 1992; Oyewole et al., 2018). Moreover, the role of the family, whether it be family modeling or family structure, influences members' hookah pipe use, since positive or negative attitudes toward smoking the hookah pipe is experienced within the family as is also influenced by how parents respond to adolescent hookah pipe use. When substance use is considered acceptable by parents, siblings, and friends, it increases the risk of use because it may be perceived that using the hookah pipe is allowable, and in some cases desirable (Hawkins et al., 1992). Interestingly, Brook et al. (1990) examined the role of older brothers in younger brothers' substance use and found that an older brother's substance use can influence a younger brother's substance use. This finding is supported in this study as well as in the study by Oyewole et al. (2018) which showed that older brothers play a central role in the lives of their younger siblings, especially regarding substance use, particularly hookah pipe use (Hawkins et al., 1992).

Furthermore, the role of mental health also needs to be considered. Once again, this study as well as that of Oyewole et al. (2018) found conclusive evidence that mental health conditions, such as anxiety and depression, plays a major role in adolescent hookah pipe use. Adolescence is a period marked by significant developmental changes. Thus, the use of substances may have a negative effect on their development. This is especially true for adolescents with symptoms of anxiety, depression, or other psychosocial problems because smoking the hookah pipe may be used as a coping mechanism to ameliorate their condition, but could instead be exacerbating their already difficult situation (Schulte \& Hser, 2013). Despite having mental health conditions, curiosity and experimentation remains a common feature of adolescents. Therefore, specific interventions need to be aimed at meeting the emotional needs of adolescents who use the hookah pipe in an attempt to minimize hookah pipe use and create awareness about the harmful effects of using substances and having a mental health condition or psychosocial stressor.

A study by Perikleous et al. (2018) focusing on e-cigarettes found similar results to this study. The study found that curiosity, male gender, lower school performance, studying at a disadvantaged school, increasing age and gender, using other substances, family or peer smoking, or being in employment and being affluent increases the odds of using e-cigarettes (Perikleous et al., 2018). Akl et al. (2015) conducted a narrative review assessing the determinants of hookah pipe use in young people aged 10-29 years. The study revealed that hookah pipe use is on the rise because of the positive attitude toward hookah pipe smoking, perceptions of addictive properties and health hazards (less harmful than cigarette smoking), and ability to quit. Furthermore, youth provided the following reasons for smoking the hookah pipe: entertainment; relaxation; to escape boredom; curiosity and experimentation; to 
socialize; and the resultant positive somatic experience that engages almost all the sensestaste, smell, sight, sound, and touch. Hookah pipe users expressed that they associate use with culture and heritage.

The findings of all these studies indicate that the determinants of hookah pipe use and other tobacco products are similar. However, Siddiqi (2018) identified that the interventions that are effective in tobacco cessation cannot simply be applied to hookah pipe users because it has been found that tobacco cessation interventions do not yield the same results for hookah pipe cessation. This means that an alternative intervention specifically aimed at reducing hookah pipe use is needed. Conventional tobacco interventions use methods, such as the drug varenicline, behavioral counseling and support to address some of the psychological aspects of addiction. This is achieved by short-term prevention and early intervention support by means of supportive, educational, or counseling sessions (Dogar et al., 2014; Lipkus et al., 2011). Siddiqi (2018) argues that conventional tobacco cessation interventions lack the social element that is prominent in hookah pipe smoking, since hookah pipe users mainly smoke with friends and family. Additionally, when planning an intervention, the developmental phase and context of the target population is very important in order to captivate their attention and implement the intervention tools, skills, or practices effectively(Bailey et al., 2015).

\section{Limitations}

In this study, a number of limitations were identified. Although 12 databases were used with broad search categories, only articles published in journals within the included databases were accessed for this study. This means that there may be other relevant studies describing the determinants of hookah pipe use that have not been included in this study. Due to the heterogeneity of the methodology, data, and analysis of the trends within the identified studies, it was challenging to compare the studies in terms of the strengths and weaknesses of factors related to determinants of hookah pipe use. Not all studies provided sufficient information about the strength of the determinants, as some only provided descriptive data making it difficult to ascertain whether this was a determinant for adolescent hookah pipe use or not. Some studies allowed the age group to extend beyond the years of adolescence making it difficult to clearly say that the determinants are specific to adolescents. The majority of the studies drew their samples from the school setting, which means that adolescents that do not attend school are not accounted for-this may or may not have yielded additional determinants of hookah pipe use. Lastly, we did not include studies prior to 2007 and studies in languages other than English, inclusion of these articles may have yielded more results.

\section{Recommendations}

Based on the findings of this study, assessment, prevention, and treatment recommendations are provided for practitioners and researchers. Assessment could include an understanding of the adolescent's current home, school, and family circumstances; physical and mental health challenges; substance use and patterns of use; knowledge, beliefs, and attitudes toward smoking; existing coping strategies; and adolescents' perception of their authority figures' ideas of hookah pipe smoking. The results of these assessments allow clinicians to plan treatment strategies and researchers to identify and fill gaps in hookah pipe research in order to form a basis to propose interventions. The target population for prevention strategies should not only include adolescents, but also people who have a direct impact on the lives of adolescents. In addition, we argue that prevention activities should occur where they are accessible to the target audience, and can be incorporated into school curriculums, doctor visits, and life-skills sessions offered by organizations offering psychosocial support. This study found that advertisements encouraged hookah pipe smoking. This finding highlights the influential role of advertisements on viewers' lives. Therefore, advertisements advocating healthier alternatives to hookah pipe smoking, preventing hookah pipe use, and communicating the risks of hookah pipe smoking should be 
prioritized. Other age appropriate social events happening in the community should be marketed through various mediums, thereby capturing and redirecting the interests of adolescents away from attending a hookah bars or lounges. Awareness campaigns are needed in the school and community setting to educate teachers, learners, and families about the implications of hookah pipe use as well as the impact of allowing younger children to witness or smoke with parents, older siblings, or other family members. Since hookah pipe use increases with age, it is necessary to intervene as early as possible with prevention and early intervention activities to prevent adolescent hookah pipe use. In terms of research, there is a need to gain an understanding of the role of the family in hookah pipe use. Also, comparative studies can be done between users and non-users to determine the significant differences between these two groups of adolescents. In terms of treatment, interventions should be holistic in nature, taking the individual, family, school, peers, and other factors into account. As noted in the study, all these factors have an integral role in hookah pipe use. Treatment encompasses an array of activities including parent education and support sessions emphasizing the need to monitor and supervise adolescents and their activities, toolkits to understand adolescent development, understanding how the hookah pipe can be a gateway to other substances, group therapy, life skills, peer mentoring, leadership activities, and ideas on how to use pocket money wisely. Interventions must be tailored for the specific population and context. It is very important that beneficiaries of the treatment feel respected and valued-this will encourage attendance and cooperation. Treatment must occur in a space and setting where the adolescent will feel comfortable attending, for example, a park may be a more conducive environment than a clinic. Since hookah pipe smoking is a social phenomenon, the intervention needs to incorporate social elements so that attending the treatment is appealing. From a research perspective, it would be interesting to note the determinants of hookah pipe use for other age groups. Determining what drives males and females to use the hookah pipe will be helpful to decide whether an alternative intervention is needed for males and females, which in turn will guide the development of relevant and appropriate interventions. This is a noteworthy point as this study found that being male increases the odds of hookah pipe smoking. However, the other determinants can be true for males and females. Thus, the question is raised, "what makes males more likely to smoke the hookah pipe than females?" Determining adolescents' motivations and identifying what needs are being met by hookah smoking would also produce an invaluable study on the subject. A review can be done of existing interventions to retrieve previous guideline recommendations aimed at reducing hookah pipe use. Lastly, studies should be conducted to propose a potential intervention that could reduce hookah pipe use amongst adolescents.

\section{Conclusion}

The findings highlight that numerous factors contribute to adolescent hookah pipe use. These findings also suggest that there is an interplay of family, school, friends, and individual factors that determine hookah pipe use. While friends, family use, and existing substance use appear to be the strongest determinants of hookah pipe use, individual factors, such as race, context, religion, and screen time were found not to be strong determinants of adolescent hookah pipe use. Hookah pipe use should be included in clinically and empirically validated assessments as well as using evidence-based practices when addressing adolescent hookah pipe use. The use of evidencedbased assessments and practice will aid future investigators in examining adolescents' hookah pipe use and effectively reduce such behaviors. This review is a good starting point for further discussion and work on developing impactful interventions to reduce hookah pipe use.

\section{Funding}

This work was supported by the Health and Welfare Sector Education and Training Authority [17/PGRB/L000335] and the National Institute for the Humanities and Social Sciences [SDS17/1878]. 


\section{ORCID}

Zainab Kader (D) http://orcid.org/0000-0001-9120-8242

Nicolette Vanessa Roman (iD http://orcid.org/0000-00024506-437X

Rik Crutzen (iD) http://orcid.org/0000-0002-3731-6610

\section{References}

Akl, E. A., Ward, K. D., Bteddini, D., Khaliel, R., Alexander, A. C., Lotfi, T., Alaouie, H., \& Afifi, R. A. (2015). The allure of the waterpipe: A narrative review of factors affecting the epidemic rise in waterpipe smoking among young persons globally. Tobacco Control, 24(1), i13-i21. https://doi.org/10.1136/tobaccocontrol-2014051906.

Al Agili, D. E., \& Park, H. K. (2012). The prevalence and determinants of tobacco use among adolescents in Saudi Arabia. The Journal of School Health, 82(3), 131-138. https://doi.org/10.1111/j.1746-1561.2011.00676.x.

Alavijeh, F. Z., Raisi, Z., Asadollahi, A., Irani, R. D., \& Kalhori, S. R. N. (2016). Impact of training high school female students in Ahvaz, Iran in the social skills required to avoid the use of drugs. Electronic Physician, 8(5), 23-46. https://doi.org/10.19082/2346.

Al-Lawati, J. A., Muula, A. S., Hilmi, S. A., \& Rudatsikira, E. (2008). Prevalence and determinants of waterpipe tobacco use among adolescents in Oman. Sultan Qaboos University Medical Journal, 8(1), 37-43. https:/doi.org/ $10.19082 / 2346$.

Amin, T. T., Amr, M. A. M., Zaza, B. O., \& Kaliyadan, F. (2012). Predictors of waterpipe smoking among secondary school adolescents in Al Hassa, Saudi Arabia. International Journal of Behavioral Medicine, 19(3), 324-335. https://doi.org/10.1007/s12529-011-9169-2.

Bailey, J., Mann, S., Wayal, S., Hunter, R., Free, C., Abraham, C., \& Murray, E. (2015). Sexual health promotion for young people delivered via digital media: A scoping review. Public Health Research, 3(13), 1-119. https:// doi.org/10.3310/phr03130.

Baker, O. G., \& Rice, V. (2008). Predictors of narghile (water-pipe) smoking in a sample of American Arab Yemeni adolescents. Journal of Transcultural Nursing: Official Journal of the Transcultural Nursing Society, 19(1), 24-32. https://doi.org/10.1177/1043659607309141.

Bracken, B. K., Rodolico, J., \& Hill, K. P. (2013). Sex, age, and progression of drug use in adolescents admitted for substance use disorder treatment in the northeastern United States: Comparison with a national survey. Substance Abuse, 34(3), 263-272. https://doi.org/10.1080/ 08897077.2013.770424.

Brook, J. S., Whiteman, M., Gordon, A. S., \& Brook, D. W. (1990). The role of older brothers in younger brothers' drug use viewed in the context of parent and peer influences. The Journal of Genetic Psychology, 151(1), 59-75. https://doi.org/10.1080/00221325.1990.9914644.
Case-Smith, J., \& O'Brien, J. C. (2014). Occupational therapy for children and adolescents (7th ed.). Elsevier Health Sciences.

Castañeda, G., Barnett, T. E., Soule, E. K., \& Young, M. E. (2016). Hookah smoking behavior initiation in the context of Millennials. Public Health, 137, 124-130. https:// doi.org/10.1016/j.puhe.2016.02.013.

Charandabi, S., Mirghafourvand, M., Tavananezhad, N., \& Karkhaneh, M. (2015). Prevalence of cigarette and water pipe smoking and their predictors among Iranian adolescents. International Journal of Adolescent Medicine and Health, 27(3), 291-298. https://doi.org/10.1515/ijamh2014-0028.

Combrink, A., Irwin, N., Laudin, G., Naidoo, K., Plagerson, S., \& Mathee, A. (2010). High prevalence of hookah smoking among secondary school students in a disadvantaged community in Johannesburg. South African Medical Journal, 100(5), 297-299. https://doi.org/10.7196/SAMJ. 3965.

Critical Appraisal Skill Programme. (2014). CASP checklists. Critical appraisal skills programme (CASP): Making sense of evidence. http://www.casp-uk.net/\#!casp-tools-checklists/c18f8.

Daniels, K. E., \& Roman, N. V. (2013). A descriptive study of the perceptions and behaviors of waterpipe use by university students in the Western Cape, South Africa. Tobacco Induced Diseases, 11(1), 4-8. https://doi.org/10. 1186/1617-9625-11-4.

Dogar, O., Jawad, M., Shah, S. K., Newell, J. N., Kanaan, M., Khan, M. A., \& Siddiqi, K. (2014). Effect of cessation interventions on hookah smoking: Post-hoc analysis of a cluster-randomized controlled trial. Nicotine \& Tobacco Research: Official Journal of the Society for Research on Nicotine and Tobacco, 16(6), 682-688. https://doi.org/10. 1093/ntr/ntt211.

Fakhari, A., Mohammadpoorasl, A., Nedjat, S., Sharif Hosseini, M., \& Fotouhi, A. (2015). Hookah smoking in high school students and its determinants in Iran: A longitudinal study. American Journal of Men's Health, 9(3), 186-192. https://doi.org/10.1177/155798831453523.

Fedele, D. A., Barnett, T. E., Dekevich, D., Gibson-Young, L. M., Martinasek, M., \& Jagger, M. A. (2016). Prevalence of and beliefs about electronic cigarettes and hookah among high school students with asthma. Annals of Epidemiology, 26(12), 865-869. https://doi.org/10.1016/j. annepidem.2016.10.004.

Fielder, R. L., Carey, K. B., \& Carey, M. P. (2012). Predictors of initiation of hookah tobacco smoking: A one-year prospective study of first-year college women. Psychology of Addictive Behaviors: Journal of the Society of Psychologists in Addictive Behaviors, 26(4), 963-968. https://doi.org/10.1037/a0028344.

Gilmore, K. J., \& Meersand, P. (2014). Normal child and adolescent development: A psychodynamic primer. American Psychiatric Association.

Hammal, F., Mock, J., Ward, K. D., Eissenberg, T., \& Maziak, W. (2008). A pleasure among friends: How 
narghile (waterpipe) smoking differs from cigarette smoking in Syria. Tobacco Control, 17(2), e3. https://doi.org/ 10.1136/tc.2007.020529.

Haroon, M., Munir, A., Mahmud, W., \& Hyder, O. (2014). Knowledge, attitude, and practice of water-pipe smoking among medical students in Rawalpindi. Pakistan. Journal of Pakistan Medical Association, 64(2), 155-158.

Haskins, M. (2011). Drugs: A user's guide. Random House.

Hawkins, J. D., Catalano, R. F., \& Miller, J. Y. (1992). Risk and protective factors for alcohol and other drug problems in adolescence and early adulthood: Implications for substance abuse prevention. Psychological Bulletin, 112(1), 64-105.https://doi.org/10.1037/0033-2909.112.1.64.

Hussain, H. Y., \& Satar, B. A. A. (2013). Prevalence and determinants of tobacco use among Iraqi adolescents: Iraq GYTS 2012. Tobacco Induced Diseases, 11(1), 14-14.https://doi.org/10.1186/1617-9625-11-14.

Jacobs, L., Roman, N. V., \& Schenk, C. (2015). Gender performativity and addiction within the family: Focus on the hookah. Gender Behaviour, 13(2), 6753-6759.

Jawad, M., Nakkash, R. T., Mahfoud, Z., Bteddini, D., Haddad, P., \& Afifi, R. A. (2015). Parental smoking and exposure to environmental tobacco smoke are associated with waterpipe smoking among youth: Results from a national survey in Lebanon. Public Health, 129(4), 370-376. https://doi.org/10.1016/j.puhe.2015.01.011.

Jawad, M., Wilson, A., Lee, J. T., Jawad, S., Hamilton, F. L., \& Millett, C. (2013). Prevalence and predictors of water pipe and cigarette smoking among secondary school students in London. Nicotine \& Tobacco Research, 15(12), 2069-2075. https://doi.org/10.1093/ntr/ntt103.

Kandel, D., \& Kandel, E. (2015). The gateway hypothesis of substance abuse: Developmental, biological and societal perspectives. Acta Paediatrica, 104(2), 130-137. https:// doi.org/10.1111/apa.12851.

Karimy, M., Niknami, S., Heidarnia, A. R., Hajizadeh, I., \& Montazeri, A. (2013). Prevalence and determinants of male adolescents' smoking in Iran: An explanation based on the theory of planned behavior. Iranian Red Crescent Medical Journal, 15(3), 187-193. https://doi.org/10.5812/ ircmj.3378.

Kelishadi, R., Heshmat, R., Shahsanai, A., Djalalinia, S., Motlagh, M. E., Keikha, M., Ardalan, G., Najafi, F., Khoramdad, M., Asayesh, H., \& Qorbani, M. (2016). Determinants of tobacco and hookah smoking in a nationally representative sample of Iranian children and adolescents: The Caspian-IV Study. Iranian Red Crescent Medical Journal, 18(8), 1-13. https://doi.org/10.5812/ ircmj.31099.

Koçak, A. O., Akbaş, İ., \& Çakır, Z. (2017). Carbon monoxide poisoning due to water pipe smoking: Case series. Journal of Emergency Medicine, 8(2), 27-30. https://doi. org/10.5152/jemcr.2016.1706

Kola, A. J. (2014). Students' academic performance and importance of continuous assessment [ca] in basic and digital electronics. American Journal of Contemporary Scientific Research, 1(3), 9-16.
Lipkus, I. M., Eissenberg, T., Schwartz-Bloom, R. D., Prokhoro, A. V., \& Levy, J. (2011). Affecting perceptions of harm and addiction among college waterpipe tobacco smokers. Nicotine \& Tobacco Research: Official Journal of the Society for Research on Nicotine and Tobacco, 13(7), 599-610. https://doi.org/10.1093/ntr/ntr049.

Louw, D. A., \& Louw, A. E. (2014). Child and adolescent development. Psychology Publications.

Merianos, A. L., Mancuso, T. F., Gordon, J. S., Wood, K. J., Cimperman, K. A., \& Mahabee-Gittens, E. M. (2018). Dual-and polytobacco/nicotine product use trends in a national sample of high school students. American Journal of Health Promotion, 32(5), 1280-1290. https:// doi.org/10.1177/0890117117743361.

Moamary, M. S., Al Ghobain, M. A., Al Shehri, S. N., Alfayez, A. I., Gasmelseed, A. Y., \& Al-Hajjaj, M. S. (2012). The prevalence and characteristics of water-pipe smoking among high school students in Saudi Arabia. Journal of Infection and Public Health, 5(2), 159-168. https://doi.org/10.1016/j.jiph.2012.01.002.

Moher, D., Liberati, A., Tetzlaff, J., \& Altman, D. G. (2009). The PRISMA group. Preferred reporting items for systematic reviews and meta-analyses: The PRISMA statement. Annals of Internal Medicine, 151(4), 264-269. https://doi.org/10.7326/0003-4819-151-4-20090818000135.

Nohair, S. F. (2011). Prevalence of smoking and its related behaviors and beliefs among secondary school students in Riyadh, Saudi Arabia. International Journal of Health Sciences, 5(1), 51-57.

Oyewole, B. K., Animasahun, V. J., \& Chapman, H. J. (2018). Tobacco use in Nigerian youth: A systematic review. PLOS One, 13(5), e0196362. https://doi.org/10. 1371/journal.pone.0196362.

Palamar, J. J., Zhou, S., Sherman, S., \& Weitzman, M. (2014). Hookah use among US high school seniors. Pediatrics, 134(2), 227-210. https://doi.org/10.1542/peds. 2014-0538.

Perikleous, E. P., Steiropoulos, P., Paraskakis, E., Constantinidis, T. C., \& Nena, E. (2018). E-Cigarette use among adolescents: An overview of the literature and future perspectives. Frontiers in Public Health, 6(86), 86-13. https://doi.org/10.3389/fpubh.2018.00086.

Reveles, C. C., Segri, N. J., \& Botelho, C. (2013). Factors associated with hookah use initiation among adolescents. Journal de Pediatria, 89(6), 583-587. https://doi.org/10. 1016/j.jped.2013.08.001.

Roman, N. V., \& Frantz, J. M. (2013). The prevalence of intimate partner violence in the family: A systematic review of the implications for adolescents in Africa. Family Practice, 30(3), 256-265. https://doi.org/10.1093/ fampra/cms084.

Roman, N. V., Schenck, C., Jacobs, L., \& September, S. J. (2017). Hookah use: Can families be a risk factor for future addiction? Journal of Child \& Adolescent Substance Abuse, 26(1), 11-17. https://doi.org/10.1080/1067828X. 2016.1175985 . 
Roohafza, H., Heidari, K., Alinia, T., Omidi, R., Sadeghi, M., Andalib, E., Ajami, A., \& Sarrafzadegan, N. (2015). Smoking motivators are different among cigarette and waterpipe smokers: The results of ITUPP. Journal of Epidemiology and Global Health, 5(3), 249-258. https:// doi.org/10.1016/j.jegh.2014.12.003.

Roohafza, H., Kasaei, Z., Heidari, K., Omidi, R., Alinia, T., Naji, M., Jaberifar, M., \& Sadeghi, M. (2015). Better view on attitudes and perceived parental reactions behind waterpipe smoking among Iranian students. Journal of Research in Medical Sciences, 20(11), 1032-1038. https:// doi.org/10.4103/1735-1995.172812.

Roskin, J., \& Aveyard, P. (2009). Canadian and English students' beliefs about waterpipe smoking: A qualitative study. BMC Public Health, 9, 10-17. https://doi.org/10. 1186/1471-2458-9-10.

Schulte, M. T., \& Hser, Y. I. (2013). Substance use and associated health conditions throughout the lifespan. Public Health Reviews, 35(2), 1-27. https://doi.org/10.1007/ BF03391702.

Senkubuge, F., Mayosi, B. M. (2012). The state of the national health research system in South Africa. South African Health Review, 13, 141-150. https://hdl.handle. net/10520/EJC133692.

Sepetdjian, E., Shihadeh, A., \& Saliba, N. A. (2008). Measurement of 16 polycyclic aromatic hydrocarbons in narghile waterpipe tobacco smoke. Food and Chemical Toxicology: An International Journal Published for the British Industrial Biological Research Association, 46(5), 1582-1590. https://doi.org/10.1016/j.fct.2007.12.028.

Shujaat, N. G., Idris, S. H., Chatha, M. R., Aftab, M., \& Afzal, S. (2013). Attitudes, practice and addiction towards water-pipe/shisha smoking in Lahore City. Pakistan Oral \& Dental Journal, 33(3), 518-522.

Siddiqi, K. (2018). Shisha addiction may be stronger than cigarette addiction. https://theconversation.com/shishaaddiction-may-be-stronger-than-cigarette-addiction102058?utm_campaign=Echobox\&utm_medium=Social\& utm_source=Facebook\#Echobox $=1536318246$

Smith, J. R., Novotny, T. E., Edland, S. D., Hofstetter, C. R., Lindsay, S. P., \& Al-Delaimy, W. K. (2011). Determinants of hookah use among high school students. Nicotine \& Tobacco Research: Official Journal of the Society for Research on Nicotine and Tobacco, 13(7), 565-572. https://doi.org/10.1093/ntr/ntr041.

Soneji, S., Barrington-Trimis, J. L., Wills, T. A., Leventhal, A. M., Unger, J. B., Gibson, L. A., Yang, J., Primack, B. A., Andrews, J. A., Miech, R. A., Spindle, T. R., Dick, D. M., Eissenberg, T., Hornik, R. C., Dang, R., \& Sargent, J. D. (2017). Association between initial use of e-cigarettes and subsequent cigarette smoking among adolescents and young adults: A systematic review and meta- analysis. JAMA Pediatrics, 171(8), 788-797. https://doi. org/10.1001/jamapediatrics.2017.1488.

Sterling, K. L., \& Mermelstein, R. (2011). Examining hookah smoking among a cohort of adolescent ever smokers. Nicotine \& Tobacco Research, 13(12), 1202-1209. https:// doi.org/10.1093/ntr/ntr146.

Sugar, M. (2014). Female adolescent development (2nd ed.). Routledge Taylor \& Francis Group.

Tamim, H., Al-Sahab, B., Akkary, G., Ghanem, M., Tamim, N., El Roueiheb, Z., Kanj, M., \& Afifi, R. (2007). Cigarette and nargileh smoking practices among school students in Beirut. American Journal of Health Behavior, 31(1), 56-63. https://doi.org/10.5993/AJHB.31.1.6.

Theron, A., Schultz, C., Ker, J. A., \& Falzone, N. (2010). Carboxyhaemoglobin levels in water-pipe and cigarette smokers. Suid-Afrikaanse Tydskrif Vir Geneeskunde [South African Medical Journal], 100(2), 122-124. https:// doi.org/10.7196/samj.3462.

Urrutia-Pereira, M., Oliano, V. J., Aranda, C. S., Mallol, J., \& Solé, D. (2017). Prevalence and factors associated with smoking among adolescents. Journal de Pediatria, 93(3), 230-237. https://doi.org/10.1016/j.jped.2016.07.003.

Van der Merwe, N., Banoobhai, T., Gqweta, A., Gwala, A., Masiea, T., Misra, M., \& Zweigenthal, V. (2013). Hookah pipe smoking among health sciences students. South African Medical Journal=Suid-Afrikaanse Tydskrif Vir Geneeskunde, 103(11), 847-749. https://doi.org/10.7196/ SAMJ.7448.

Waziry, R., Jawad, M., Ballout, R. A., Al Akel, M., \& Akl, E. A. (2017). The effects of waterpipe tobacco smoking on health outcomes: An updated systematic review and meta-analysis. International Journal of Epidemiology, 46(1), 32-43. https://doi.org/10.1093/ije/dyw021.

World Health Organization (WHO). (2005). Advisory note waterpipe tobacco smoking: Health effects, research needs and recommended actions by regulators. World Health Organization.

World Health Organization (WHO). (2015). Advisory note: Waterpipe tobacco smoking: health effects, research needs and recommended actions for regulators (2nd ed.). World Health Organization.

World Health Organization (WHO). (2018). Department of gender, women and health. 10 facts on gender and tobacco. http://www.who.int/gender/documents/10facts_ gender_tobacco_en.pdf.

Ziaei, R., Mohammadi, R., Dastgiri, S., Viitasara, E., Rahimi, V. A., Jeddi, A., \& Soares, J. (2016). The prevalence, attitudes, and correlates of waterpipe smoking among high school students in Iran: A cross-sectional study. International Journal of Behavioral Medicine, 23(6), 686-696. https://doi.org/10.1007/s12529-016-9555-x. 